\title{
Mensuração da interdisciplinaridade nos cursos de graduação em Administração
}

\author{
Interdisciplinarity measurement \\ in Business Graduation Courses
}

\author{
Luciana Oranges Cezarino ${ }^{1}$ \\ ${ }^{1}$ Universidade Federal de Uberlândia | Faculdade de Gestão e Negócios \\ Uberlândia | MG | Brasil. Contato: lcezarino@gmail.com \\ http://orcid.org/0000-0001-5556-8275 \\ Hamilton Luiz Corrêa ${ }^{2}$ \\ ${ }^{2}$ Universidade de São Paulo | Departamento de Administração \\ São Paulo | SP | Brasil. Contato: hamillco@usp.br \\ http://orcid.org/0000-0002-1172-8537
}

Resumo: O artigo propõe um modelo de mensuração da interdisciplinaridade nos cursos de graduação em
Administração. A survey eletrônica foi realizada nos cursos avaliados pelo Enade 2009 e os dados
tratados pela Análise Fatorial e de Conglomerados. A média de interdisciplinaridade dos cursos em
relação aos fatores dimensionados no modelo foi de 2,63 em uma escala de 0 a 10 , considerado baixo,
ou seja, tudo indica os projetos de interdisciplinaridade são escassos nos cursos de Administração no
Brasil. A análise fatorial revelou alto índice de correlação entre os dados e de 17 variáveis reuniu
duas dimensões de mensuração: "organização" e "didática". Com a análise de conglomerados foi
constatado que o grupo que apresenta cursos com maior presença da variável articulação é que obteve
melhores índices de interdisciplinaridade.

Palavras-chave: Interdisciplinaridade. Administração. Graduação.

Abstract: The paper aims to propose a measurement model of interdisciplinarity on Business undergraduate
courses. An electronic survey was designed to evaluated courses by Enade 2009, data was analyzed by
factorial and cluster analysis. The interdisciplinarity average was 2,63 in a scale 0 to 10 , considered
low. Evidences indicate that interdisciplinarity projects are rare on Business undergraduate courses in
Brazil. Factorial analysis revealed high levels of correlation between data and from 17 variables meet
them into two dimensions "organization" and "didatics". Cluster analysis indicated that the group that
presented more interdisciplinarity has deeper presence of articulation variable.

Key words: Interdisciplinarity. Management. Undergraduate business course.

DOI: http://dx.doi.org/10.1590/S1414-40772019000100010

Recebido em: 27 de fevereiro de $2017 \quad$ Aprovado em: 12 de setembro de 2018

Este é um artigo publicado em acesso aberto (Open Access) sob a licença Creative Commons Attribution Non-Commercial, que permite uso, distribuição e reprodução em qualquer meio, sem restrições desde que sem fins comerciais e que o trabalho original seja corretamente citado. https://creativecommons.org/licenses/by-nc/4.0/ 


\section{Introdução}

$\mathrm{O}$ ensino em Administração atravessa momentos árduos. $\mathrm{O}$ avanço tecnológico da informação, a mudança de comportamento do estudante, as avaliações institucionais, a pressão por produtividade de pesquisa e os rankings de comparação contribuem para o ambiente turbulento. No Brasil os cursos também sofrem dificuldade em desenvolver metodologias capazes de abranger a conexão entre partes apresentada pela realidade, com dilemas sobre o perfil do formando. É cada vez mais difícil preparar cidadãos criativos capazes de lidar com modelos flexíveis de gestão, que convivam bem com as mudanças, tenham capacidade de se autogerir, de se articular nas redes e que sejam capazes de aprender por toda a vida.

Os cursos de Administração se mostram inertes diante das mudanças no mundo dos negócios ou no mínimo estão atrasados em relação à necessidade de introdução de novas técnicas e métodos para que desempenhem bem sua função. Além disso, embora pareça distante, a crítica à formação fragmentada evidencia o esgotamento do ensino de Administração pela sua transformação em mera sequência de conteúdos.

No entanto, é nesse ambiente universitário que se abre uma oportunidade para que se supere o excesso de especialização que limitou a formação desses profissionais. Nesta linha, a interdisciplinaridade surge como uma possibilidade de enfrentamento destes desafios. Segundo Fazenda (2006) a interdisciplinaridade é a arte do tecido que nunca deixa ocorrer o divórcio entre seus elementos, entretanto, de um tecido bem traçado e flexível. Trata-se de um conceito abordado desde a crise da ciência moderna que propõe a integração de conhecimentos para uma compreensão mais abrangente da realidade de um fenômeno. Nascido na França, o termo se desenvolveu como ideia a ser investigada a partir do final dos anos 1960, fazendo parte das investigações acadêmicas até a atualidade.

O discurso da interdisciplinaridade é utilizado em diversos âmbitos: academia, organizações, empresas, grupos de discussão, associações e governos. Diversas áreas do saber discutem ou já discutiram o tema. Os benefícios da interdisciplinaridade na educação estão na capacidade de o aluno estabelecer diálogos entre os conteúdos, fazendo com que ele utilize seu conhecimento na busca de soluções em seu dia a dia.

Todavia, quando se inicia a investigação sobre o assunto, percebe-se que não há uma iniciativa nem na academia nem nas associações de cursos de administração que tenha esse tema em foco. Os trabalhos são teóricos exibindo definições de interdisciplinaridade e suas contribuições são mais voltadas à formação humanística. Quando aplicados à administração, 
são relatos pontuais de cursos que empreenderam inovações pedagógicas em direção à interdisciplinaridade. Existem inúmeros trabalhos a respeito de métodos de ensino em administração, formação docente em administração e ainda alguns a respeito da gestão de escolas de Administração. Contudo, no que diz respeito à interdisciplinaridade incorporada ao contexto educacional das escolas de Administração, as publicações são escassas, formando uma lacuna entre saberes.

Ausentam-se informações generalizadas disponíveis para que se esclareça como as escolas de Administração no Brasil e no exterior experimentam a aplicação da interdisciplinaridade em suas atividades didáticas ou como conduzem atividades que indiretamente resultam em interdisciplinaridade. Tampouco se dispõe de trabalhos acadêmicos que se dediquem à tarefa de definir o que seria a interdisciplinaridade nas escolas de Administração. Não há clareza acerca da definição do conceito quando aplicado à administração, dificultando estudos descritivos e conclusivos.

Portanto, antes da realização de pesquisas conclusivas ou da proposição de práticas, faz-se necessário explorar a realidade dos cursos e identificar as variáveis prioritárias que compõem as práticas de interdisciplinaridade no ensino de administração.

\section{Objetivos e método}

O tema da interdisciplinaridade no ensino em administração faz-se pertinente no momento em que há discussão nos meios acadêmicos e no ambiente corporativo sobre a eficácia da formação do gestor no nível de graduação. Aulas sequenciais, conteúdo especializado, ênfase em pesquisa são condicionantes de um status quo questionado e pouco transformado.

As escolas de Administração têm sido criticadas pela capacidade de prover ensino que acompanhe a trajetória das empresas e as demandas de habilidades técnicas e comportamentais do gestor contemporâneo (HAMBRICK, 1993; FRIGA; BETTIS; SULLIVAN, 2003; LORANGE, 2005; PFEFFER; FONG, 2004; BENNIS, O’TOOLE, 2005; CORNUEL, 2005; HAY, 2008). O método de aula expositiva e trabalhos em grupo, apesar de amplamente adotado pelas escolas de Administração no Brasil, está defasado e desconectado da forma como o aluno pensa e se comunica. A sequência de conteúdos sobre as áreas funcionais da Administração e suas ramificações faz com que o aluno imagine que sua atuação será técnica, ou seja, basta aplicar os modelos e tudo será resolvido. Quando o aluno se depara com a realidade da organização, normalmente na fase de estágio, percebe que seu 
referencial é de difícil aplicação e que a interação com a causa e o efeito das ações sobre a empresa não são descritas em modelos lineares de gestão. $\mathrm{O}$ gestor acaba desenvolvendo, por autoaprendizagem, meios de liderar, de desenvolver seus subordinados, de se relacionar com pares e superiores, absorvendo o comportamento da organização em que trabalha como exemplo de postura e costumes. O ensino de administração, quando apresentado de forma linear, acaba por limitar o pensamento do aluno à "decoreba" de conceitos e siglas, não apresentando a ele a complexidade de desafios que o mundo corporativo proporciona.

A partir deste contexto, foi possível desenvolver um modelo que apresenta capacidade de demonstrar qual o nível de interdisciplinaridade que as escolas de Administração empregam no ensino de graduação próprio da realidade brasileira.

Este trabalho questiona: Qual o nível de interdisciplinaridade do ensino de administração nos cursos de graduação do Brasil? Para que essa pergunta possa ser respondida, este trabalho possui o seguinte objetivo geral: propor um modelo de mensuração da interdisciplinaridade nas escolas de Administração brasileiras.

O trabalho caracteriza-se como uma pesquisa descritiva com abordagem quantitativa. A pesquisa descritiva é dedicada à caracterização de variáveis de uma população ou ainda o desenvolvimento de associações entre variáveis. Segundo a pesquisa descritiva é intermediária entre a pesquisa exploratória e conclusiva e significa identificar, relatar, comparar entre outros aspectos (RAUPP; BEUREN, 2003).

Por sua vez, a abordagem quantitativa consiste nos estudos organizacionais, a mensuração de opiniões, reações, hábitos e atitudes em um universo, por meio de uma amostra que o represente estatisticamente (TERENCE; ESCRIVÃO FILHO, 2006).

A abordagem quantitativa deste trabalho caracterizou-se por:

a) Construção de uma amostra de contatos de coordenadores de curso de Administração, com base na listagem do ENADE de 2009 - sendo esta a última listagem disponibilizada para domínio público pelo MEC, que inclui os resultados para o curso de Administração de empresas;

b) Elaboração do questionário em escala de Likert e envio dos formulários eletrônicos;

c) Análise Fatorial para confirmação dos construtos identificados teoricamente;

d) Análise de Conglomerados, tendo por base os construtos identificados;

A amostra, segundo Mattar (1996, p. 270-272), foi construída por conveniência de resposta e, portanto, todos os resultados referentes à coleta de dados quantitativos devem refletir apenas os resultados da amostra e não da população de respondentes. Ao longo de 2012, a amostra de contatos dos coordenadores de curso de graduação foi sendo construída e 
foi possível encontrar em websites das IES, currículos Lattes e indicações dos próprios respondentes o total de 1.145 respondentes com o devido endereço eletrônico.

A inferência estatística versou sobre a análise fatorial e a análise de conglomerados. A principal função das diferentes técnicas de análise fatorial é reduzir uma grande quantidade de variáveis observadas em um número menor de fatores (FIGUEIREDO FILHO; SILVA JUNIOR, 2010) enquanto que a análise de conglomerados, ou clusters, se dispõe a agrupar dados de acordo com determinadas variáveis mostrando grupos mais homogêneos dentre a amostra estudada.

\section{Referencial teórico}

A interdisciplinaridade tem como objetivo integrar os conteúdos, estabelecendo um diálogo entre as disciplinas. Não pretende erradicar as disciplinas - até porque outro tipo de divisão se estabeleceria - mas, sim, promover um encadeamento de conhecimento para a solução de problemas. Busca compreensão da realidade por meio da aplicação do conhecimento, mesmo que ele esteja alocado em conteúdos de disciplinas diferentes.

O prefixo "inter", dentre as diversas conotações que podemos lhe atribuir, tem o significado de "troca", "reciprocidade" entre disciplina, ensino, instrução, ciência. Logo, a interdisciplinaridade pode ser compreendida como sendo um ato de troca, de reciprocidade entre as disciplinas ou ciências, ou melhor, entre as diversas áreas do conhecimento (FAZENDA, 1999).

Para Olga Pombo, a interdisciplinaridade se diferencia das demais pelo seu próprio conceito: "combinação de quaisquer disciplinas com vistas à compreensão de um objeto a partir da confluência de pontos de vista diferentes e tendo como objetivo final a elaboração de uma síntese relativamente ao objeto comum" (POMBO, 2012). A interdisciplinaridade corresponde a uma nova consciência da realidade, a um novo modo de pensar que resulta num ato de troca, de reciprocidade e integração entre áreas diferentes do conhecimento, visando tanto à produção de novos conhecimentos, como a resolução de problemas de modo global e abrangente (FAVARÃO; ARAÚJO, 2004, p. 107). Ela questiona a segmentação entre os diferentes campos do conhecimento produzida por uma abordagem que não leva em conta a inter-relação e a influência entre eles. Questiona também a visão compartimentada (disciplinar) da realidade, sobre a qual o conhecimento historicamente se constituiu (FREITAS; NEUENFELDT, 2005). Busca-se estabelecer o sentido de unidade, de um todo na diversidade, mediante uma visão de conjunto, permitindo ao homem tornar significativas as 
informações desarticuladas que vem recebendo (GARRUTTI; SANTOS, 2004). Para Pombo (2012), é a combinação de quaisquer disciplinas com vistas à compreensão de um objeto a partir da confluência de pontos de vista diferentes e tendo como objetivo final a elaboração de uma síntese relativamente ao objeto comum.

Recorrente em diversas áreas de conhecimento, apresenta maior ocorrência em países francófonos, germano-escandinavos ou nórdicos, anglo-saxônicos e no Brasil. Possui uma grande massa de estudos concentrados na área de educação, pedagogia, filosofia e alguns ensaios na área de administração. Cada campo do conhecimento trabalha o conceito sob sua própria perspectiva, construindo grande quantidade de textos com enfoques e aplicações variados. Esse referencial teórico difuso dificulta a identificação precisa de sua origem e o acompanhamento de seu desenvolvimento, forçando o pesquisador que pretende estabelecer qualquer instrumentalização de pesquisa sobre interdisciplinaridade a ter de descrever seu conceito.

A Figura 1 identifica as principais escolas de pensamento interdisciplinar de acordo com a linha temporal de publicação dos textos, bem como apresenta algumas características das diferentes abordagens:

\section{Figura 1 - Origens Teóricas do Conceito de Interdisciplinaridade}

\begin{tabular}{|c|c|c|c|c|}
\hline & Escola Francesa & $\begin{array}{l}\text { Escola Germano- } \\
\text { Escandinava } \\
\text { (Nórdica) }\end{array}$ & $\begin{array}{l}\text { Escola } \\
\text { Anglo- } \\
\text { Saxônica }\end{array}$ & $\begin{array}{l}\text { Escola } \\
\text { Brasileira }\end{array}$ \\
\hline Décadas de 70-90 & \multicolumn{2}{|c|}{$\begin{array}{l}\text { Perspectiva filosófica ou } \\
\text { Epistemológica (interações } \\
\text { internas) }\end{array}$} & & \\
\hline A partir de 1990 & & \multicolumn{2}{|c|}{$\begin{array}{l}\text { Perspectiva instrumental } \\
\text { (interações externas) }\end{array}$} & $\begin{array}{l}\text { Perspectiva } \\
\text { fenomenológica }\end{array}$ \\
\hline $\begin{array}{l}\text { OBJETIVODE } \\
\text { PESQUISA }\end{array}$ & \multicolumn{2}{|c|}{$\begin{array}{l}\text { Pesquisa por uma síntese } \\
\text { conceitual: hierarquização de } \\
\text { disciplinase metadisciplina }\end{array}$} & $\begin{array}{l}\text { Pesquisa por } \\
\text { repostasa } \\
\text { problemas da } \\
\text { sociedade }\end{array}$ & $\begin{array}{l}\text { Pesquisa por } \\
\text { novosmétodos } \\
\text { de ensino }\end{array}$ \\
\hline \multirow[t]{2}{*}{ CARATERÍSTICA } & \multicolumn{2}{|c|}{$\begin{array}{l}\text { Unificação do saber científico:. } \\
\text { Reflexão sobre os saberes } \\
\text { disciplinares em interação }\end{array}$} & $\begin{array}{l}\text { Saber útil, } \\
\text { operacional }\end{array}$ & $\begin{array}{l}\text { Relação entre } \\
\text { ensinoe } \\
\text { pesquisa }\end{array}$ \\
\hline & & MICA & DE PROJETO & DIDÁTICA \\
\hline
\end{tabular}


Percebe-se, pela investigação na literatura, que as implicações da interdisciplinaridade no processo de aprendizado poderia trazer muitos avanços e benefícios à formação do profissional de administração. Para Fazenda (2006, p. 32) a interdisciplinaridade possibilita interação entre o vivido e o estudado, permite a análise de situações globais - além dos limites de seu próprio sistema conceitual - e reafirma a condição para a educação permanente, posto que, por meio da subjetividade, é possível a troca contínua de experiências.

\section{Resultados}

São apresentadas as respostas recebidas das análises quantitativas: fatorial e clusters. A Tabela 1 demonstra as comunalidades entre as variáveis. Apesar da baixa variação comum que a variável de discussão da interdisciplinaridade apresenta (TEMADEDISCUSSÃO), a mesma foi mantida na amostra. Pela clara exposição da divisão dos dados, não se fez necessária a rotação dos vetores dos dados pela AF. Os resultados mostram dois fatores nãoobserváveis na análise de dados.

Tabela 1 - Resultado das Comunalidades da Análise Fatorial

\begin{tabular}{l|r|r}
\hline & Initial & Extraction \\
\hline Disciplina "interdisciplinadora" - DISCIPLINA & 1,000 &, 866 \\
\hline Mudanças periódicas na grade - MUDANÇAS & 1,000 &, 846 \\
\hline Presença de projeto extraclasse - PROJETO & 1,000 &, 851 \\
\hline Planejamento da grade para interdisciplinaridade - PLANEJGRADE & 1,000 &, 863 \\
\hline Interdisciplinaridade no planejamento pedagógico - PLANEJPEDAG & 1,000 &, 889 \\
\hline Há estudos que mostram sobreposição - SOBREPOSIÇÃO & 1,000 &, 863 \\
\hline A interdisciplinaridade é tema de discussão - TEMADEDISCUSSÃO & 1,000 &, 518 \\
\hline Relação linha de pesquisa com ensino em sala de aula - RELACPESQUISA & 1,000 &, 916 \\
\hline Relação problemas da sociedade com o ensino em sala de aula - RELACPROBLEM & 1,000 &, 925 \\
\hline Relação conhecimento de pesquisa - INTPESQUISA & 1,000 &, 821 \\
\hline Monitoramento de resultados - MONITRESULT & 1,000 &, 779 \\
\hline Utiliza-se PBL - PBL & 1,000 &, 864 \\
\hline Utiliza-se simulação - SIMULAÇÃO & 1,000 &, 875 \\
\hline Utilizam-se estudos de caso - ESTCASOS & 1,000 &, 800 \\
\hline Avaliação única - AVALUNICA & 1,000 &, 905 \\
\hline Compartilhamento de disciplina entre docentes com integração de conteúdo - COMPDISC & 1,000 &, 888 \\
\hline Trabalhos de várias disciplinas - TRABALHOS & 1,000 &, 616 \\
\hline Extraction Method: Principal Component Analysis. &, &, \\
\hline
\end{tabular}

A matriz fatorial, após a rotação dos fatores, permitiu uma classificação de variáveis em cada um dos fatores: FATOR 1 - DISCIPLINA, PROJETO, PBL/TBL, SIMULAÇÃO, ESTCASOS, AVALUNICA, COMPDISC, TRABALHOS e FATOR 2 - MUDANÇAS, 
PLANEJGRADE, PLANEJPEDAG, SOBREPOSIÇÃO, TEMADEDISCUSSÃO, RELACPESQUISA, RELACPROBLEM, INTPESQUISA e MINITRESULT.

Tabela 2 - Matriz de Componentes

\begin{tabular}{|c|c|c|}
\hline \multicolumn{3}{|l|}{ Rotated Component Matrix ${ }^{a}$} \\
\hline & \multicolumn{2}{|c|}{ Component } \\
\hline & 1 & 2 \\
\hline Disciplina "interdisciplinadora" - DISCIPLINA & ,923 &,- 116 \\
\hline Mudanças periódicas na grade - MUDANÇAS &, 084 & ,916 \\
\hline Presença de projeto extraclasse - PROJETO & ,913 &, 128 \\
\hline Planejamento da grade para interdisciplinaridade - PLANEJGRADE & ,082 &,- 925 \\
\hline Interdisciplinaridade no planejamento pedagógico - PLANEJPEDAG &, 163 &,- 929 \\
\hline Há estudos que mostram sobreposição - SOBREPOSIÇÃO & 414 & ,832 \\
\hline A interdisciplinaridade é tema de discussão - TEMADEDISCUSSÃO &, 123 & ,709 \\
\hline $\begin{array}{l}\text { Relação linha de pesquisa com ensino em sala de aula - } \\
\text { RELACPESQUISA }\end{array}$ &, 268 & ,803 \\
\hline $\begin{array}{l}\text { Relação problemas da sociedade com o ensino em sala de aula- } \\
\text { RELACPROBLEM }\end{array}$ &, 170 &, 809 \\
\hline Relação conhecimento de pesquisa - INTPESQUISA &, 127 & ,654 \\
\hline Monitoramento de resultados - MONITRESULT &, 170 &, 764 \\
\hline Utiliza-se PBL - PBL & ,898 &,- 239 \\
\hline Utiliza-se simulação - SIMULAÇÃO &, 805 &,- 476 \\
\hline Utilizam-se estudos de caso - ESTCASOS &, 838 &,- 314 \\
\hline Avaliação única - AVALUNICA &, 903 &,- 299 \\
\hline $\begin{array}{l}\text { Compartilhamento de disciplina entre docentes com integração de } \\
\text { conteúdo - COMPDISC }\end{array}$ & ,895 &,- 296 \\
\hline Trabalhos de várias disciplinas - TRABALHOS &, 753 &,- 221 \\
\hline \multicolumn{3}{|l|}{ Extraction Method: Principal Component Analysis. } \\
\hline \multicolumn{3}{|l|}{ Rotation Method: Varimax with Kaiser Normalization } \\
\hline a. 2 components extracted. & & \\
\hline
\end{tabular}

A análise fatorial revelou alto índice de correlação entre os dados e de 17 variáveis reuniu duas dimensões de mensuração: "organização" e "didática". As variáveis que pertenciam à dimensão "estrutura curricular" mostraram-se altamente correlacionadas com as variáveis pertencentes às atividades didáticas. A análise fatorial arranjou as variáveis de acordo com as suas correlações. 
Figura 2 - Resultado da Agrupamento da Análise Fatorial

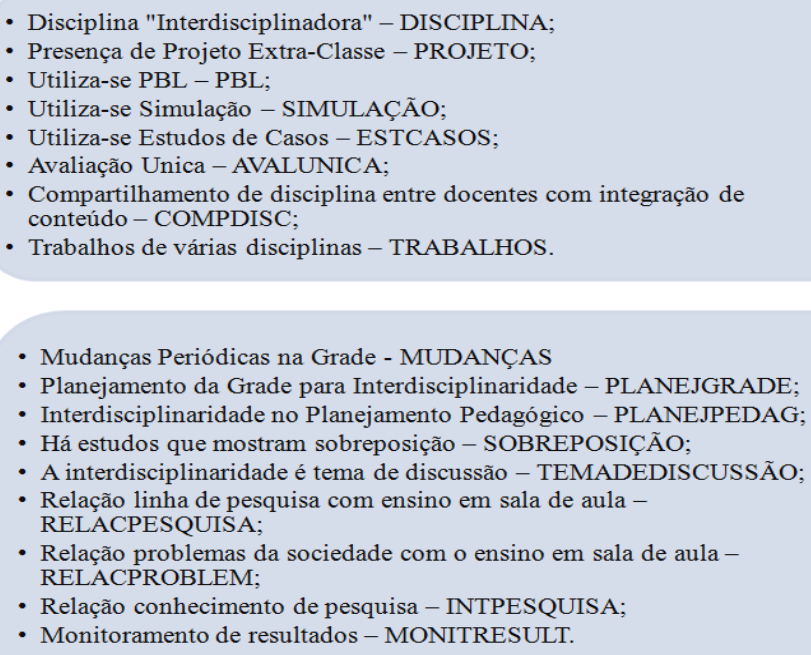

A última fase da pesquisa compreendeu a divisão dos cursos da amostra de acordo com o nível de interdisciplinaridade apresentados.

O grupo 1 foi denominado como "Potenciais", pelo valor representado pelo fator "didática", mostrando que o curso proporciona técnicas de ensino voltadas para o aluno, trabalhos interdisciplinares ou outras variáveis ligadas à interdisciplinaridade no ensino. Por outro lado, há menor qualificação e uma tendência para a formação mista do coordenador em relação aos demais grupos. Desta forma, este grupo foi considerado em potencial desde que o fator "didática" pudesse ser aproveitado e controlado pela coordenação.

O grupo 2 apresentou os maiores índices de interdisciplinaridade. Algumas características diferenciam o grupo, além da interdisciplinaridade. É o que apresenta maior investimento em pesquisa, maior nível de qualificação do coordenador, com maior tendência para a formação do coordenador mais concentrada na área de Administração. Um ponto interessante é que se trata de um grupo de IES públicas e privadas, não limitando a interdisciplinaridade à fonte de financiamento. São cursos mais distribuídos geograficamente, com destaque para a região Sul, que aparece como segunda detentora de cursos deste grupo, atrás do Sudeste. Outro ponto importante é o fato de o contrato com dedicação à pesquisa apresentar os maiores índices da amostra. O fator "organização" é o mais alto dos grupos, mostrando maior articulação do curso à interdisciplinaridade. Por esta razão foi chamado de "Articulado". 
O grupo 3 diferencia-se pouco do grupo 1. Foi chamado de "Regular" pelo fato de apresentar qualificação média do coordenador, formação mais concentrada na área de Administração e baixo investimento em pesquisa. Têm melhor distribuição geográfica e seus índices mostram-se medianos em relação aos apresentados pelos demais grupos.

O grupo 4 foi chamado de cursos "Sequenciados". Isso porque os índices de interdisciplinaridade são os mais baixos da amostra. A qualificação do coordenador é a mais baixa, e há mais áreas na sua formação em graduação. São estruturas menores, centralizadas no Sudeste, que têm um investimento mínimo em pesquisa expresso nos contratos dos docentes.

Figura 3 - Representação dos quatro grupos de cursos da amostra de acordo com o nível de interdisciplinaridade

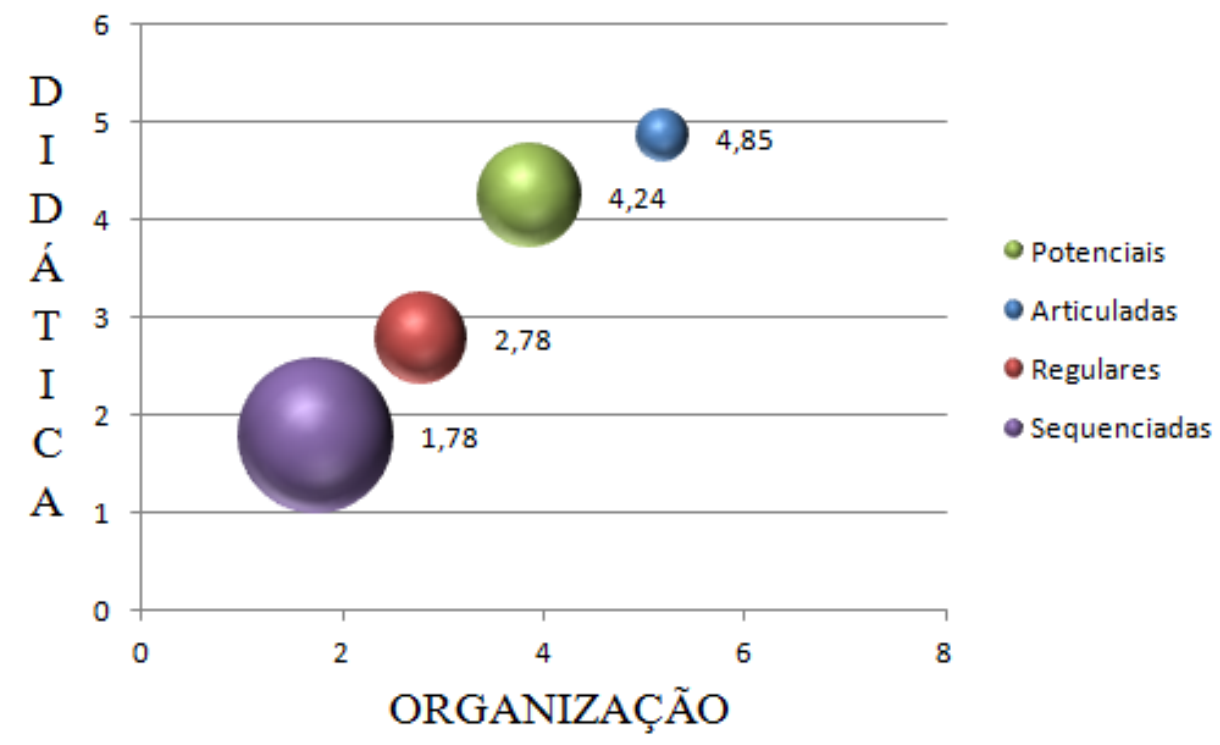

\section{Considerações}

O estudo teve como objetivo propor um modelo de mensuração da interdisciplinaridade no ensino em administração. Este objetivo foi alcançado por meio de um arquétipo composto pela análise fatorial e análise de conglomerados. Ambas análises contribuíram para definição de quais eram os fatores que diferenciavam a interdisciplinaridade desenvolvida pelos cursos enquanto que a análise de conglomerados dividiu a amostra em grupos que apresentavam características semelhantes destes fatores. A média interdisciplinar dos cursos em relação aos fatores dimensionados no modelo foi de 2,63 em uma escala de 0 a 10, considerado baixo, ou seja, tudo indica os projetos de interdisciplinaridade são escassos nos cursos de Administração no Brasil 
As variáveis que isoladamente mostraram média maior em toda a amostra foram a intensidade de utilização do estudo de caso nas disciplinas $(8,9)$, a presença da interdisciplinaridade no planejamento pedagógico $(7,2)$ e a intensidade de utilização do estudo simulação empresarial $(6,6)$. São atividades superficiais diante das possibilidades de atividades que a interdisciplinaridade permite desenvolver.

O grupo 4, das escolas sequenciadas, responsável por $52,3 \%$ dos respondentes da amostra, exibe um quadro inquietante em relação ao nível de interdisciplinaridade. Há características como: contratos que não incluem dedicação à pesquisa, coordenadores com formação mista com maioria em Administração e baixa qualificação do coordenador. Os dados revelam que os índices tanto em "organização" como em "didática” são baixos, não há preocupação com nem estímulo à interdisciplinaridade no ensino. São cursos organizados sequencialmente, que ainda não permitem que o aluno possua contato com a atividade de pesquisa e expanda seu raciocínio.

Os grupos que apresentam valores intermediários têm maior enfoque no fator “didática". Didática diz respeito ao método de ensino empregado em sala de aula, além de trabalhos, projetos e avaliações que integram o conteúdo de mais de uma disciplina. Dessa forma, é possível perceber indícios de que há leve movimentação em como apresentar o conteúdo e cobrar resultados de aprendizagem do aluno, mas isso se faz de forma não controlada ou até mesmo em ilhas de interdisciplinaridade. Muitas vezes, como mencionado na entrevista 1, um docente consegue concatenar conteúdos de disciplinas e executa uma atividade durante o curso, mas isso não significa que há interdisciplinaridade no ensino do curso, em geral.

O grupo considerado com maior grau de interdisciplinaridade no ensino, com média de 4,85, mostrou-se insignificante em termos de tamanho, 5,07\% da amostra. Não se percebe neste grupo qualquer categorização contundente, como ser majoritariamente formado por cursos de IES públicas ou privadas, por exemplo. Ao contrário, o que se percebe é que o grupo é formado por praticamente o mesmo perfil de escolas que o restante da amostra, porém com contratos de trabalho que incluem dedicação à pesquisa, coordenadores formados em sua maioria em Administração e com qualificação superior à média.

Quantitativamente este grupo contrasta com os demais, com maior distância no fator "organização". Percebe-se que estes cursos conseguem obter certo avanço frente às principais dificuldades apontadas pelos coordenadores, seja nas IES públicas, seja nas privadas, havendo maior comprometimento do corpo docente com o ensino. Nas IES públicas, o foco se volta para a pesquisa, o que enfatiza ainda mais o ensino focado em disciplinas isoladas, dividindo- 
se o conteúdo em áreas determinadas que são ministradas por professores gabaritados naquele assunto especificamente. Nas IES privadas, o problema advém dos contratos em tempo parcial, professores horistas que precisam complementar a renda com o trabalho na educação. Não se sabe se este grupo alcança estes índices por meio de contratos mais sofisticados, prováveis remunerações e benefícios mais atrativos aos docentes ou por sua integração tendo em vista um melhoramento do ensino coletivamente. $O$ fato é que o papel do fator "organização" mostra articulação das atividades interdisciplinares de ensino.

Deve se fazer uma reflexão a respeito dos fatores causadores da não realização da interdisciplinaridade no curso, bem como das atividades didáticas voltadas à sequencialidade de conteúdos. Para isso é preciso entender as variáveis que compõem cada fator e pesquisar como se dão esses processos no interior da gestão dos cursos. Percebe-se que o modelo de mensuração proposto exibiu o diagnóstico de interdisciplinaridade nos cursos de Administração e sua intenção não extrapola as possíveis ações para correção da situação apurada.

Diante dessas informações, é trabalho das IES, através de seu corpo docente e sua coordenação, diagnosticar com maior precisão o seu caso particular diante da média dos fatores apresentados e, a partir daí, criarem estratégias específicas para enfrentar suas dificuldades. Agindo desta forma, as abordagens da interdisciplinaridade feitas pela escola nórdica e pela escola fenomenológica estarão sendo contempladas, pois a interdisciplinaridade passará a ser tratada como projeto, como resultado do processo de ensino no curso de Administração. Contudo, não deixa de ser algo fenomenológico, pois vai buscar, dentro de suas peculiaridades, soluções para o estímulo à interdisciplinaridade.

Entretanto, não se pode propor uma mudança radical nas escolas de graduação em Administração. Afinal, “a construção do conhecimento interdisciplinar se processa por estágios ou etapas de maturação de consciência", salienta Lück (2002, p. 65).

O que é possível considerar é que se o descompasso da escola de Administração com as demandas do mundo dos negócios (HAMBRICK, 1993; FRIGA; BETTIS; SULLIVAN, 2003; LORANGE, 2005; PFEFFER; FONG, 2004; BENNIS; O’TOOLE, 2005; CORNUEL, 2005; HAY, 2008) tem como um de seus sintomas a falta de interdisciplinaridade com que convive o estudante de Administração. Daí se conclui que as escolas representantes da amostra estudada estão comprovadamente obsoletas. A transformação da escola de Administração em uma organização gerenciável com processos e objetivos poderia minimizar estas condições. A gestão da interdisciplinaridade passa a ser uma das responsabilidades do curso de Administração, agregando valor, sendo fonte de vantagem competitiva e 
principalmente melhorando a qualidade da educação em administração de qualquer curso. Concordando com Friga, Bettis e Sullivan (2003) e Jurse (2012), as escolas apresentadas na amostra carecem mais na dimensão "organização", ou seja, que o ensino seja controlado, gerenciado, e não que apenas boa formação, pesquisa e infraestrutura sejam a receita para um bom curso.

Também é possível retomar a ideia de Zell (2001) de que a maior perda da escola de Administração foi o enfraquecimento da didática. Como visto na amostra pesquisada, não se podem fazer distinções entre IES públicas e privadas. Há indícios, pela fala dos coordenadores nas entrevistas, de que tanto as IES públicas como as privadas não têm o ensino como foco principal. Nas IES públicas, os docentes centralizam seus esforços na pesquisa, enquanto que nas IES privadas os alunos são tratados como "clientes" e o ensino passa a ser cada vez mais "spoon-fead" ou, como chamamos no Brasil, "mastigado". Essas duas percepções levam a crer que a escola de Administração não conseguiu atingir uma melhora da didática e, posteriormente, uma melhora do ensino dos futuros administradores. Não se pode apontar culpados por esta situação, haja vista que as escolas tiveram um crescimento exponencial desde a década de 1960 até os dias de hoje. Mais do que isso, seu ambiente alterou-se significativamente (AAHEA, 2012).

Porém, como destaca Palmade (1979), é certo que não se pode impor a interdisciplinaridade, fazendo com que corpo docente e coordenação executem projetos prontos. O que é possível é permitir a criação de ambientes e espaços para que se identifiquem formas próprias a cada escola, além de haver uma necessidade de a direção da escola valorizar a interdisciplinaridade e alocar responsabilidades para sua operacionalização.

O trabalho empreendeu esforços interdisciplinares em duas áreas de pesquisa academicamente distintas, a educação e a administração. O universo da educação, a linguagem, os conceitos abstratos são um campo novo de conhecimento para o administrador. Ao se ver desafiado pelas exigências de mercado e pelas necessidades de aperfeiçoamento de sua formação, os educadores em administração terão de transpor esta barreira disciplinar entre os dois universos, desafio este enfrentado no processo de pesquisa e escrita deste trabalho. 


\section{Referências}

AAHEA. AMERICAN ASSOCIATION FOR HIGHER EDUCATION. Scanning the Environment: AAHEA's President Reports on Trends in Higher Education. AAHE Bulletin, 1998. Disponível em: http://www.aahea.org/bulletins/articles/scanning.htm. Acesso em: 27 mar. 2012.

BENNIS, Warren G.; O'TOOLE, James. How business schools lost their way. Harvard Business Review, USA, v. 83, n. 5, p. 96-104, 2005.

CORNUEL, Eric. The role of business schools in society. Journal of Management Development, USA, v. 24, n. 9, p. 819-29, 2005.

FAVARÃO, Neide Rodrigues Lago; ARAÚJO, Cíntia de Souza Alferes. Importância da interdisciplinaridade no ensino superior. Educere - Revista da Educação da UNIPAR, Umuarama, v. 4, n. 2, p. 103-115, 2004.

FAZENDA, Ivani Catarina Arantes. Virtude da força nas práticas interdisciplinares. São Paulo: Papirus, 1999.

FAZENDA, Ivani Catarina Arantes. Interdisciplinaridade: história, teoria e pesquisa. São Paulo: Papirus, 2006.

FIGUEIREDO FILHO, D. B.; SILVA JÚNIOR, José Alexandre. Visão além do alcance: uma introdução à análise fatorial. Opinião Pública, Campinas, v. 16, n. 1, p. 160-185, 2010.

FREITAS, D. S., NEUENFELDT, A. E. Interdisciplinaridade na escola: limites e possibilidades. In: ENCONTRO IBERO-AMERICANO, 4., 2005, Lajeado, RS. Anais [...]. Lageado: UNIVATES, 2005.

FRIGA, Paul N.; BETTIS, Richard. A.; SULLIVAN, Robert. S. Changes in Graduate Management Education and New Business School Strategies for the 21st Century. Academy of Management Learning \& Education, USA, v. 2, n. 3, p. 233-49, 2003. Disponível em: http://search.proquest.com/docview/223298683? accountid=42153. Acesso em: 7 jan. 2012.

GARRUTTI, É. A.; SANTOS, S. R. A interdisciplinaridade como forma de superar a fragmentação do conhecimento. Revista de Iniciação Científica da FFC, Marilia, v. 4, n. 2 , 2004.

HAMBRICK, Donald. What if the Academy Actually Mattered? Academy Of Management Review, USA, v. 19, n. 1, p. 11-16, 1993, 2004.

HAY, Michael. Business Schools: A New sense of Purpose. Journal of Management Development, USA, v. 27, n. 4, p. 371-378, 2008.

JURSE, Milan. Implications of education market globalisation for business school management in transition countries. Maribor: Universidade de Maribor, Eslovênia. Disponível em: https://library.villanova.edu/Find/Summon/Record?id=FETCHproquest_dll_16711376311. Acesso em: 14 mar. 2012. 
LORANGE, Peter. Strategy means choice: also for today's business school. Journal of Management Development, USA, v. 24, n. 9, p. 783-90, 2005.

MATTAR, Fauze N. Pesquisa de marketing. São Paulo: Atlas, 1996.

PALMADE, G. Interdisciplinaridade e ideologias. Madrid: Narcea, 1979.

PFEFFER, Jeffrey; FONG, Christina. The Business School 'Business': some lessons from the US Experience. Journal of Management Studies, USA, v. 41, n. 8, p.1501-20, 2004.

POMBO, Olga. Interdisciplinaridade: conceito, problemas e perspectivas. In: POMBO, Olga. A interdisciplinaridade: reflexão e experiência. Lisboa: Universidade de Lisboa, 2012. p. 814.

RAUPP, Fabiano Maury; BEUREN, Ilse Maria. Metodologia da pesquisa aplicável às ciências sociais. In: BEUREN, Ilse Maria (org.). Como elaborar trabalhos monográficos em contabilidade: teoria e prática. 2. ed. São Paulo: Atlas, 2003. p. 76-97.

TERENCE, Ana Claudia Fernandes; ESCRIVÃO FILHO, Edmundo. Abordagem quantitativa, qualitativa e a utilização da pesquisa-ação nos estudos organizacionais. In: ENCONTRO NACIONAL DE ENGENHARIA DE PRODUÇÃO-ENEGEP, 26., 2006, Fortaleza. Anais [...]. Fortaleza: Abepro, 2006.

ZELL, Deone. The Market-driven Business School: Has the Pendulum Swung too Far? Journal of Management Inquiry, USA, v. 10, n. 4, p. 324-40, 2001. 